\title{
Goal Setting in Family Firms: Goal Diversity, Social Interactions, and Collective Commitment to Family-Centered Goals
}

\author{
Josip Kotlar \\ University of Bergamo \\ Center for Young \& Family Enterprise \\ Via Pasubio 7B, 24044 Dalmine (BG) - Italy \\ josip.kotlar@unibg.it \\ Alfredo De Massis \\ University of Bergamo \\ Center for Young \& Family Enterprise \\ Via Pasubio 7B, 24044 Dalmine (BG) - Italy \\ alfredo.demassis@unibg.it
}

Please cite as: Kotlar, J. \& De Massis, A. (2013). Goal setting in family firms:

Goal diversity, social interactions, and collective commitment to family-centered goals. Entrepreneurship Theory and Practice, 37(6). 


\title{
Goal Setting in Family Firms: Goal Diversity, Social Interactions, and Collective Commitment to Family-Centered Goals
}

\begin{abstract}
Goal setting in family firms is very complex due to the interplay between family and business systems. However, this topic is largely overlooked in family business research. In this qualitative study of goals and goal formulation processes among 76 organizational members across 19 family firms, we identify goal diversity as a direct consequence of the overlap between the family, ownership and business systems. We found that goal diversity is expressed more strongly in the proximity of generational transitions, triggering social interaction processes through which organizational members contrast their goals. Our findings suggest that different types of social interactions lead to different behaviors, with familial social interactions being more effective than professional social interactions in managing goal diversity toward the formation of collective commitment to family-centered goals.
\end{abstract}

\section{INTRODUCTION}

Goal setting, in all organizations, is a vital function through which individual goals are transformed into organizational policies and actions (Cyert \& March, 1963; Simon, 1964). For family firms, these activities are likely to be more complex owing to the unique systemic interactions between the family and the business (Habbershon, William, \& MacMillan, 2003). A family can use its power and discretion to influence decisions and foster the adoption of familycentered goals (Chua, Chrisman, \& Sharma, 1999; Chrisman et al., 2012). Given that family firms are very common (e.g., La Porta et al., 1999), and given that family-centered goals play an important role in the theory of family firms (Chrisman \& Patel, 2012; De Massis et al., forthcoming; Habbershon et al., 2003), it is surprising that only limited attention has thus far been paid to how organizational goals are determined in these organizations (De Massis et al., 2012). Thus, addressing the issues underlying the goal formulation processes in family firms appears warranted. 
The family is seen as a dominant group within the family firm (Chua et al., 1999). According to Cyert and March (1963), it follows that family-centered goals will become more salient as the family coalition increases its representation and authority within the organization. However, the relationship between family involvement and the adoption of family-centered goals is likely to be complex, and mediated and moderated by several factors (Chrisman, Chua, \& Sharma, 2005; Chrisman et al., 2012). Goal setting involves individuals, groups and firms, nevertheless, the relatively scarce studies available are limited to the firm level, typically relying on single informants (e.g., Chrisman et al. 2012; Tagiuri \& Davis, 1992) and overlooking the individual organizational member's role in the process. In this study, we attempt to broaden and refine the extant theory in the area of organizational goals and goal formulation processes in family firms by addressing the following research question: How do the individual goals of organizational members influence the organizational goals pursued by family firms?

Given the ambiguities inherent in multilevel research, qualitative methodologies were considered particularly appropriate to accomplish our purpose (Hitt et al., 2007). We undertook interviews and gathered non-participant observations and archival documents from 19 family firms; thereafter analyzing these qualitative data to disclose the unexplored dynamics of goal setting in family firms. The evidence presented in this article refines and extends current understanding of how family involvement engenders the adoption of family-centered goals in organizations, and offers new insights on intra-family succession as an ideal occasion for challenging the status quo and fostering the restabilization of new organizational goals. Finally, this study reveals the critical contribution that studying these aspects of goal setting can make to theory building in the area of organizational behavior and stakeholder management, as well as enhancing practical understanding of organizational goals in family firms. 
The article is organized as it follows: in the next section, we set the foundations for our study by reviewing insights from prior research on goal setting and from family business literature. In the third section, we outline the research design and methods. Thereafter, we present the key findings and the inductive process that led us to formulate our theoretical propositions. Finally, we discuss the implications of our findings and draw conclusions.

\section{BACKGROUND}

Organizational goals are an important yet controversial concept in organization theory (Argote \& Greve, 2007; Cyert \& March, 1963; Simon, 1964). In contrast to the economic approach of modeling firm decisions made by unitary actors, organizational theorists challenge the assumption that organizations have simple, well-defined goals and conceive work organizations as political entities in which coalitions are formed among individuals to influence the goals that the firm will pursue (Cyert \& March, 1963; Stevenson, Pearce, \& Porter, 1985). According to this perspective, organizational goals may change over time, reflecting the goal setting processes among coalitions that presumably pursue conflicting and inconsistent goals (Cyert \& March, 1963). Thus, defining the goals adopted by an organization requires specifying who is able to influence firm decisions, the elements that may affect their individual goals and, more importantly, the processes through which the individual preferences are translated into organizational policy and action (Stevenson et al., 1985).

Some researchers assume that the relative importance of different goals in an organization is a function of the power of individuals or groups of individuals in decisionmaking processes (e.g., Cameron, 1978; Pearce \& DeNisi, 1983). The theory of stakeholder salience (Mitchell, Agle, \& Wood, 1997), for example, suggests that managers pay sequential attention to internal and external stakeholders based on the evaluation of their attributes of 
power, legitimacy and urgency. However, managers are not necessarily a cohesive group (e.g., Pitcher \& Smith, 2001), and thus can only loosely be defined as a coalition. Furthermore, several organizational members can influence firm behavior through their decisions in different organization units (Simon, 1964), while goal setting processes do not necessarily follow hierarchical arrangements among coalitions (Jacobides, 2007; Pfeffer \& Salancik, 1977; Stevenson et al., 1985). Consequently, in order to avoid implementation gaps, the formulation of organizational goals cannot be limited to the top management team, but should also involve other individuals at different levels of the organization (e.g., Floyd \& Wooldridge, 1992).

According to Cyert and March (1963), organizational goals are formed through a process that is articulated in three steps: first, coalitions are formed and coalition goals are defined through internal bargaining and side payments; second, goals are stabilized and elaborated into control-systems that define policy constraints to organizational member actions; finally, organizational goals are continuously updated on experience gained (Cyert \& March, 1963, p. 33). Research in social psychology and political science provides further insights in this regard, suggesting that individuals purposefully form coalitions to pursue their goals (e.g., Pearce \& DeNisi, 1983), and that coalitions will tend to be inclusive to increase their bargaining power and maximize policy outcomes for its members (e.g., Komorita \& Chertkoff, 1973; Rosenthal, 1970). Combining the insights from this body of research with the description of goal setting processes proposed by Cyert and March (1963), Stevenson et al. (1985) concluded that the problem of defining organizational goals is closely linked to that of defining coalitions. They suggest that coalitions are continuously formed in organizations in response to variations in organizational resources, creating conflicts among organizational members and subsequent bargaining mechanisms that lead to determining joint actions. 
A key assumption in this literature stream is that occupational roles are almost completely separate from personal goals (Simon, 1964, p. 14). It follows that the examination of goal setting processes is typically abstracted from the individual motives that determine participation, and the nature of the processes is largely limited to the business sphere. These restrictions become problematic when aiming to extend these insights to the family firm context for at least two reasons. First, family members share common bonds and mutual expectations that may generate alternative, less tangible forms of side-payments (Astrachan \& Jaskiewicz, 2008). Second, relational contracting is juxtaposed to purely economic contracting in family firms (Gómez-Mejía, Nunez-Nickel, \& Gutierrez, 2001), making organizational processes highly ambiguous compared to those of non-family firms. Moreover, family business literature informs that additional complexity in coalition and organizational goal formation lies in the extent of the overlaps between the family, the ownership and the business systems, which presumably can also change over time (Habbershon et al., 2003). Prior studies have shown that providing their families with financial security and other non-economic benefits is often recognized as an important goal of owner-managers in family firms (Tagiuri \& Davis, 1992). However, not all family firms pursue family-centered goals (Westhead \& Howorth, 2007) and the relationship between family involvement and the organizational goals adopted by family firms is likely to be complex (Chrisman et al., 2012).

Although family firms are an interesting context in which to examine goal setting processes and family-centered goals are important in explaining their particularistic behaviors and outcomes (Chrisman et al., 2012; Chrisman \& Patel, 2012; Chua et al., 1999; Habbershon et al., 2003), research exploring the antecedents of family-centered goals is scarce. Extant research investigated family firm goals at the firm level, typically relying on a single informant, and thus 
neglecting the antecedents and processes that characterize goal setting in these firms. As a consequence, understanding and predicting the adoption of family-centered goals by family firms remains an important challenge for the development of a theory of the family firm. New perspectives and innovative research approaches are required to perceive the complexity of goal setting implicit in family involvement in the business, and build a more fitting theory on the adoption of family-centered goals in family firms.

\section{METHODS}

Our aim is to build theory in the area of family business organizational goals and to broaden existing theory by extending and refining the categories and relationships that have been left out of the literature (Locke, 2001). For this purpose, we conducted a theory-building qualitative study to better understand the unexplored dynamics of goal setting in family firms.

\section{Sample and Context}

Data were obtained from interviews, non-participant observations and archival documents gathered from small and medium family firms in Italy. We first identified a set of firms that could potentially be included in the study through preliminary interviews with professionals collaborating with the Center for Young and Family Enterprise (CYFE) of the University of Bergamo, which provided a preliminary list and references for 36 family firms from their professional networks of small and medium firms. After establishing contact with the CEOs and conducting preliminary interviews, we selected a subsample of 24 firms that met the following three conditions: (i) ownership majority was held by members belonging to one family, (ii) two or more family members were actively involved in the business, and (iii) the CEO perceived the firm as a family firm (Westhead, Cowling, \& Howorth, 2001). Among these, 5 CEOs declined participating due to time limitations, while we obtained informed consent from 
the CEOs of 19 family firms to conduct interviews, to participate as observers in family and business meetings and to access their archives.

The 19 family firms included in the final sample were equally distributed between manufacturing (61\%) and service (39\%) industries, as well as between industrial (56\%) and business-to-consumer industries (44\%). Firm size ranges between 17 and 206 employees with an average of 66. Firm age ranges between 13 and 206 years since foundation, the average is 31 . Seven firms are controlled by the founder generation, eight by the founder's heirs and four firms by descendants up to the sixth generation. Finally, 10 family firms are expecting an intra-family succession to occur within the next 5 years, whereas 9 family firms went through a succession in the five years prior to the study.

This sample and context was thought to be sufficiently large and diverse to provide an excellent opportunity to examine goal setting in family firms. First, the choice of focusing on small and medium firms is a reasonable compromise between the degree and nature of goal conflicts most likely to be observed. Although large firms may present greater goal conflict due to the larger number and variety of internal and external parties that are able to make claims and influence the business agenda, in smaller firms such conflicts are more likely to concern familycentered goals. Furthermore, the influence of a controlling family is more strongly felt and the interactions between family and business are more likely to be observable (Chrisman et al., 2012). Thus, our choice implied trading external validity against opportunities to gain valuable insights on the idiosyncratic outcomes engendered by the interplay between family, ownership and business systems. In addition to considerations on firm size, the inclusion of family firms that are well distributed in terms of firm age further extends the possibility of providing valuable insights into goal formulation processes in family firms. This was deemed necessary to capture 
the differences in terms of within-group alignment of family members, which is acknowledged as differing across family firms at the founding, sibling-partnership and cousin-consortium stages (Schulze, Lubatkin, \& Dino, 2003). Furthermore, the segmentation according to the family generation in control was considered important since this has been shown to affect many management processes (Schulze et al., 2003). Finally, the stage of the succession process was also considered important since, by definition, a succession is a process that implies significant organizational changes, including organizational goals (De Massis, Chua, \& Chrisman, 2008; Steier \& Miller, 2010).

Once we defined the sample of firms, in order to build and elaborate the theory we searched for a purposeful sample of family business organizational members covering a wide range of membership and role categories. Specifically, to facilitate the theory building, we searched for a context that could serve as an "extreme case" (Eisenhardt, 1989) with dynamics that are more visible than in other contexts. In particular, we chose to explore goal differences among different groups of organizational members within a general context, namely, the family firms as defined above. Consistent with the overlapping circles model, which portrays a static degree of interaction (overlap) between the family and the business (Habbershon et al., 2003), we chose to include in the study members of family firms within the dominant coalitions of the family, ownership and business entity systems.

We represent the segmentation of the family firm's organizational members by examining Chief Executive Officers (CEO), professional (non-family) top executives (PM), young generation family members (YG), family CEO spouses (CS) and old generation family members (OG). This set of organizational members maximized the differences along four dimensions that were considered particularly relevant to our study. First, we selected individuals 
that own equity shares of the firm and others that do not, since ownership is likely to affect the incentives and priorities of organizational members (Jensen \& Meckling, 1976). Second, we selected family members as well as non-family members because the latter could be expected to follow a self-serving attitude, whereas family-members are possibly more oriented towards the family firm's collectivistic goals (e.g., Corbetta \& Salvato, 2004). Third, we selected family members who are actively involved in the business and those who are not, since they may differ in terms of their power in the organization and how they perceive the family and business priorities (Schulze et al., 2003). Fourth, we selected family members that belong to the current CEO's generation, to the younger generation and to the older generation, since research has pointed to relevant differences between incumbents and descendants (De Vries, 1993).

Given these differences among the types of family firms and organizational members, we felt that this combination would provide enough distinct windows through which to view organizational member individual goals. Taken together, this sample and context provide an excellent opportunity to examine goal setting in family firms.

Using the purposeful sample of family business organizational members distributed over types of role and involvement, we collected data up to "theoretical saturation". Although guidelines to determine non-probabilistic sample sizes are virtually nonexistent (Guest, Bunce, \& Johnson, 2006), we stopped when no new information or themes were observed in the data, which resulted in a sample of 76 informants. The distribution of informants across firms and any additional information of the interviewees in the sample are presented in Table 1.

Demographically, our sample was approximately 18 percent female, with women quite uniformly distributed among members involved and not involved in the business (6 out of 14 were involved in the business), family and non-family members ( 8 out of 14 were family 
members), and family generation (4 out of 8 female family members belonged to the family generation currently leading the company, 3 to the young generation, and 1 to the old generation). Informant age ranged between 25 and 68, the average informant age is 39 .

\section{Insert Table 1 about here}

\section{Data}

The primary data collection method involved semi-structured interviews with the aforementioned informants. Initially, we obtained preliminary information by asking questions in relation to the family firm (firm background, including demographic information such as age, size and industry, historical information, information on the family generation leading the company and the succession stage, and on family involvement) and the interviewee (parental relations with the controlling family, family generation membership, share ownership and role in the company). This common set of questions allowed us to observe variations in interviewee responses across different organizational members of the family firm.

To address and specify the objectives of our analysis, and to consistently develop the interview questions, we followed a pyramidal algorithm of interview question development (Wengraf, 2001). The central research question was therefore articulated into the following theory questions: What goals do family firm organizational members pursue? How do such goals relate to the individual characteristics of the informants? How do these relationships change across family firms? How do the individual goals of family firm organizational members affect the decision making processes in family firms? From each of these theory questions, we developed those to be included in the interview protocol (for the abbreviated interview protocol see the Appendix). 
Interviews lasted between 30 minutes and two hours, and all were conducted onsite (the family firm headquarters or family home) subsequent to the informed consent of the participant. The authors recorded the interviews and took notes; all interviews were transcribed verbatim.

The utility and reliability of interviews as a form of data collection is subject to scholarly debate, some emphasize the fruitfulness and underutilization of self-reports and firsthand narratives to understand subjective work experiences (e.g., Folkman \& Moskowitz, 2000), while others stress the weaknesses of such approaches by reason of the tendency of informants to adjust their responses to maintain a positive self-image and create favorable impressions (e.g., Paulhus, 1984). For this reason, we used interviews as our primary source of data but also attempted to offset the limitations of this method by using additional methods where possible.

In particular, we continually followed informants during family and business meetings (e.g., meetings of the board of directors, family meetings, casual meetings), formulating general observations of how goals form part of everyday family and business life. Access was relatively consistent across cases, with at least three meetings observed in each firm for a total of 114 meetings. These enabled confirming informant descriptions of their organizational roles, assessing the general family business environment and observing the processes through which organizational goals are set as closely as possible. In addition, we gathered archival documents from various sources in all firms, including contracts, historical books about the organization and the family, corporate websites, news articles about the firm and the family, and firm pamphlets. Taken together, these secondary sources of data provided a richer context to understand goal setting in family firms.

\section{Data Analysis}


In order to understand the goal formulation processes in family firms, we independently read interviews, observations and archival data, applying open in vivo coding using the qualitative data analysis program NVIVO (QSR International, version 9), which also enabled exchanging memos to capture themes and broad observations. More specifically, we iteratively analyzed the qualitative data by moving back and forth between the data and an emerging structure of theoretical arguments that responded to the theory questions presented above, according to three key steps (Locke, 2001; Miles \& Huberman, 1999).

The first step consisted in creating provisional categories and first-order codes. For each theory question, we began by identifying statements on our informants' views of the world via open coding (Locke, 2001), thereafter drawing on common statements, comparable episodes and equivalent content in archival data to form provisional categories and first-order codes. Following Miles and Huberman (1999), we used a contact summary form to record the provisional categories that emerged in each data source at each point in time. At times, the revisited data did not fit well into a category, which led to either abandoning or revising a category. We began by reading all transcripts and generating contact summary sheets following specific disciplines. Once contact summary sheets were completed, we met numerous times to create theoretical categories that could be relevant to answering the theory questions. As theoretical categories were created, we went back and recoded the data to see if the codes fitted the emerging abstractions. Where this was not the case, we reviewed the "discrepant data" and revised the categories accordingly. We continued this process until both reviewers agreed.

The second step consisted in integrating first-order codes and creating second-order themes. Codes were consolidated for each group, namely, we summarized the contact forms compiled from all the data collected from CEOs, PMs, YGs, CSs and OGs into different sets of 
themes, from firms at different generations of family control and at different stages of the succession process. This stage of analysis allowed us to make a comparison across roles and identify differences within and across different types of family firms as well as changes in our variables of interest (e.g., individual goals, goal formulation processes). As we consolidated the categories, they became more theoretical and abstract, and we hence moved from open to axial coding (Locke, 2001). By way of illustrating, to answer the first theory question we started by coding statements that differentiated between right and wrong goals for the family firm, which led us to observe that organizational members attribute different connotations to identical goals. We used the theme "goal meaning" to capture these elements.

The third step involved delimiting the theory by aggregating theoretical dimensions. Once second-order themes had been generated for each theory question, we sought to aggregate the dimensions underlying these themes in an attempt to understand how different themes fitted into a coherent picture. We brainstormed alternative conceptual frameworks or models that described how these themes relate to each other and to available organizational theories. Once a possible framework was identified, we reexamined the data's fit/misfit with our emergent theoretical understanding (Locke, 2001). Figure 1 summarizes the process that we followed, showing our first-order codes, second-order themes and aggregate theoretical dimensions for each theory question.

Specifically, the aggregate theoretical dimensions shown were the ones that best explained the goals pursued by family firm organizational members and the processes through which organizational goals were formulated.

Insert Figure 1 about here

FINDINGS 
As we looked at the data from each family firm, three main findings became apparent. First, organizational members within a family firm have manifold individual goals that concur with the emergence of goal diversity, which is also affected by firm-level factors such that goal diversity appears to be more pronounced when an intra-family succession is imminent. Second, goal diversity triggers the social interaction processes through which organizational members contrast their goals in an attempt to restabilize the conflict. In particular, two different types of social interaction processes (i.e., professional and familial) were identified based on significant differences in terms of setting, norms and means of bargaining and stabilization. Third, familial social interactions appear to be more effective than professional social interactions in managing goal diversity in family firms and generating collective commitment to family-centered goals among organizational members.

In describing this process, we begin with a discussion of the goals pursued by organizational members in family firms, which helps inform on the individual-level antecedents of goal setting in family firms and, ultimately, on how goal diversity and goal conflicts arise therein. We continue by presenting the social interaction processes through which goal diversity is managed as well as their implications for organizational member commitment to familycentered goals. We conclude this section by proposing a theoretical model that integrates the findings of this study and builds new theory in the area of goal setting in family firms.

\section{Behavioral Relevance of Goal Categories: The Emergence of Goal Diversity}

A taxonomy of organizational member individual goals in four goal categories emerged from the iterative comparison of the empirical evidence and previous literature, and this contributed to answering our first theory question on the goals pursued by family firm organizational members. 


\section{Insert Table 2 about here}

The taxonomy, summarized in Table 2, is formed along the two dimensions of goal content (i.e., economic, non-economic) and goal recipient (i.e., family, non-family). The first goal category is family centered economic goals (FC-E), typically emphasized by family members committed to keeping company control in the hands of the family and to generate various forms of wealth for the family:

I made the company what it is now, and I want to see our family continue running the business through their own efforts (OG) I come from a modest family, my first goal was, and still, is to improve our lives. (CEO)

One could say, what we do is to ensure a future for our children. (CS)

A second category of goals were again oriented to benefit the family but were noneconomic in nature. In the family centered non-economic goals (FC-NE) category, we included mentions of goals such as preserving harmony within the family, promoting family social status and reputation, and maintaining a link between the family and the business identity:

I feel that maintaining a good atmosphere in the family is one of the most important drivers of the behavior of our company. (CEO)

We want to be recognized as an engine of our territory's economic development. (PM)

The long lasting values of our family must be a guiding reference for our future actions. (CEO)

The third category of goals was not explicitly oriented to the family and was strictly related to the economic aspects of business. These non-family centered economic goals (NFCEC) included disparate indicators of economic performance such as growth, survival and profit:

Increasing the value of our assets as well as the expectations of value-creation in the future are considered imperatives. (PM)

Ultimately, it is important to establish actions aimed at preserving the market position that we have achieved up to now. (CEO)

First of all, we must aspire to keeping the business alive. (OG) 
Finally, non-family centered non-economic goals (NFC-NE) were goals intended to satisfy other stakeholders than the family and were not related to economic aspects. These goals embraced the improvement and conservation of good relationships with internal and external stakeholders, such as employees and the external community:

I feel a strong responsibility towards our employees and their families. (CEO) We should keep in mind that we are part of a community that gives us a lot...We want to reciprocate with our activities. (CEO)

I think that the actions of our company must satisfy ethical requirements, without cheating or shortcuts. (YG)

While discussing these goals, the organizational members involved in the study expressed several opinions and judgments including comments in relation to their meaning (e.g., positive or negative) and their importance. We conveyed these instances into the theoretical dimension behavioral relevance of goals. Each organizational member discussed multiple goals belonging to different categories and each organizational member was also able to identify a subjective hierarchy among these goals, which allowed us to define the goal category that is most relevant to each informant. Comparative analyses of the behavioral relevance of goals by informant characteristics revealed a number of notable insights on how the relative relevance of the different goal categories relates to individual membership within the family, ownership and business systems, and to the characteristics of the family firm ${ }^{1}$.

To briefly present the key insights derived from this body of evidence, we summarize our findings on the determinants of organizational member individual goals into three general observations. These observations answer our theory questions in terms of individual goals and how these goals relate to the characteristics of the informants and firms. They contextualize and reinforce existing understanding of family firms as a result of unique systemic conditions

\footnotetext{
${ }^{1}$ For the sake of brevity, these prefatory analyses have been omitted. The full analyses are available from the authors on request.
} 
engendered by the interaction of the family unit, the business entity and individual family members (Habbershon et al., 2003). This implicitly incorporates the idea that systemic interactions in family firms can lead to the coexistence of manifold individual goals contributing to the formation of organizational goals. In addition, these observations serve to introduce the individual-level antecedents of goal setting in family firms for the purpose of examining how individuals influence organizational goals in family firms:

Observation 1: Organizational member goals in the family firm reflect their membership in the family, ownership and business systems.

Observation 2: The individual goals associated with a given configuration of organizational membership vary across firms at different generations of family control.

Observation 3: The individual goals associated with a given configuration of organizational membership vary across firms at different stages of intra-family succession.

Overall, these initial observations on organizational member individual goals call into question the implicit assumptions in family business research that controlling families share common aspirations and values, and that family involvement can thus be considered a homogeneous dimension that consistently predicts the extent to which the dominant coalition in the firm is likely to pursue family-centered goals (e.g., Chrisman et al., 2012; Chrisman et al., 2005). A more nuanced portrait of family member goals emerged from our empirical evidence suggesting that family members embrace a much wider spectrum of individual goals than previously assumed, which provides some support to the contention that goal alignment among family members is not a realistic expectation (Villanueva \& Sapienza, 2009). Based on this initial body of empirical evidence, we argue that the interactions between the family, ownership and business systems generate goal diversity within a family firm, and that such goal diversity 
increases as the number and membership assortment of organizational members involved in the upper echelons of a family firm increases. Consistent with other diversity constructs in organizational literature, goal diversity is proposed as a compositional construct (Harrison \& Klein, 2007) that describes the distribution of goals among the organizational members contributing to decision making in a family firm, and can be captured by the width of the range of goals actively pursued by members of an organization.

The fact that the generation of family control and the stage of intra-family succession influence the individual goals of organizational members suggests that succession may also be related to goal diversity in family firms. The analysis at the firm level presented in Figure 2 extends this suspicion. After proxying goal diversity by the number of different goals that emerged from our interviews in each firm, we plotted this on a timeline reporting the time when intra-family succession took place (or was expected to take place, as stated by informants). From this additional analysis emerged that the observed goal diversity is greater in family firms that are temporally closer to the occurrence of an intra-family succession.

\section{Insert Figure 2 about here}

Thus, the imminence of an intra-family succession appears to momentarily disrupt goal diversity, which becomes more perceptible in proximity to generational transitions. Thus, we propose:

Proposition 1: Goal diversity is more strongly expressed when an intra-family succession is imminent.

To summarize, the findings presented so far reveal that the factors determining organizational member individual goals interact to generate goal diversity. The observations linking individual organizational member goals to the concept of goal diversity and Proposition 1 offer a novel conceptualization of complexity in family firms. 
This enables recognizing the variety of goals pursued by organizational members belonging to different systems or system interactions. It also allows capturing the degree of organization-level animosity related to goal matters within a family firm while contextualizing the formulation of organizational goals in organization theory (e.g., Cyert \& March, 1963; Simon, 1964) to the distinctive case of family firms. In the next section, we uncover the implications of goal diversity for goal formation processes in family firms.

\section{Professional and Familial Social Interaction Processes}

To enable understanding goal setting in family firms entailed exploring organizational member individual goals and their determinants, which led us to develop the concept of goal diversity that encapsulates the complex set of inputs to goal formulation processes in family firms. This, however, was only the first step. More importantly, our analysis revealed the means by which organizational member goals are processed in everyday organizational and family life, which were deemed essential to understanding the distinctive features of goal setting in these firms. Family firms are assumed to engage in particularistic behaviors as they place great emphasis on family-centered goals (Chrisman et al., 2012; Chrisman \& Patel, 2012), but how do family firms manage goal diversity arising from family involvement in ownership and management?

Our data reveal that goal diversity triggers goal-centered social interaction processes among organizational members, during which we observed the individuals actively making voice (i.e., behaviors that challenge the status quo and attempt to promote change in the organization) and explicitly countering family versus non-family centered goals. In particular, we observed two major stages that characterize the practical patterns through which organizational members 
interacted (see Figure 1): the bargaining mode (i.e., what they do), and stabilization of their goals (i.e., how they formulate organizational goals). Bargaining was observed when organizational members conveyed interpersonal interactions in the form of either settlements or disputes. Settlements consisted in negotiations of goals among two or more organizational members with symmetrical influences. For instance, a settlement episode was observed during a meeting between a CEO and a minority owner who also serves as a PM. The parties were discussing an issue related to next year's budget and, when the PM expressed some concerns relating to the dividend policy, the two started negotiating until the percentage of profits to be reinvested in the firm was increased. After the meeting, the PM commented: "This is not the first time our views have differed, but after all, we respect each other and both believe we can always find a compromise as long as we want it” (PM).

Alternatively, goal divergences were managed through disputes in which typically a more influential party (either individual or sub-coalition) imposed goals on a weaker party during a verbal fight. For example, a recently appointed CEO described when he first asked his father (the former CEO) for a share of the firm's equity: "Two years ago it became quite clear that I would take his position sooner or later, so I started telling him about how the company could grow, improve results ... I wanted to become a shareholder to put things in motion, but he was not in favor and left me without much of an explanation ... Only now do I understand that he was simply waiting to understand my sister's and my cousins' expectations about the future of the company before making any decision" (CEO). In some episodes, but not always, bargaining was followed by a stabilization mechanism observed in the form of formal contracts, agreements and other means through which the goals resulting from a bargaining process were formalized and 
turned into a consistent course of action for the members involved (see Figure 1). Based on this evidence, we thus propose:

Proposition 2: The greater the goal diversity, the higher the occurrence of goalcentered social interaction processes.

Beyond identifying goal-centered social interactions as processes through which familycentered goals are bargained and stabilized, the most striking part of our evidence was the emergence of two distinct types of social interactions: professional and familial social interaction processes. Strong differences between these two types of goal-centered social interaction processes were clearly evident in terms of settings, norms and means.

First, professional social interactions occurred exclusively in the business setting during programmed meetings such as board meetings, management meetings, inter-departmental meetings and formal bilateral meetings. For example, a professional manager was very specific about the arrangement when interacting with a young generation family member he encountered in the corridor: "They must respect my time ...Even if the issue was urgent, I told him we could meet another time, I was busy" (PM). To the contrary, familial social interactions were rarely programmed and took place in both business and family contexts, including family councils, private meetings in family member offices, home visits, Sunday lunches and dinners. To illustrate, a young generation family member said: "Sometimes it is also frustrating, I talk about business priorities and objectives at home even more than at the workplace" (YG); a professional managers said: "Sometimes I visit him [a YG] at home in the evening ... His door is always open to me ... The atmosphere is different, I feel relaxed and free to express my concerns" (PM). Furthermore, organizational members taking part in professional social interactions had welldefined roles, as indicated by attire, following hierarchical structures, lack of interruptions and questions asked at the end. To illustrate, organizational members often waited for the appropriate 
occasion to discuss their concerns through professional social interactions: "I didn't want to disturb him, so I waited until the following Friday for our usual weekly assessment” (PM); “I waited for the next board meeting to express my concerns" (PM). On the other hand, familial social interactions took place in different circumstances (such as in the firm corridor, while watching a soccer game or during dinner) among organizational members with undefined and often ambiguous roles. Individuals started conversations spontaneously while interruptions and distractions were common: "When I have something in mind I just go into his [the CEO's] office and sit down” (YG); “After dinner ... I don't remember how we [the CEO and a PM] started discussing my daughter's career in the firm" (CEO).

Moreover, professional and familial social interactions contrast administrative with affective bargaining, and formal with social stabilization. In professional social interactions, bargaining took place through promises of rewards and threats of sanctions. When individual goals differed in a professional social interaction, the discussion typically centered on the reciprocal benefits and losses of each member, negotiation followed a top-down flow involving repeated attempts to convince the individuals at the lower levels of organizational hierarchy, often by way of economic benefits. For example, a CEO used economic threats to persuade a non-family shareholder to create a financial instrument to support younger family members: "I was really unhappy with this closure, after all I am the majority owner, I would have preferred to make a joint decision. ... I threatened to revise his equity stake" (CEO). As a consequence, stabilization in professional social interactions followed the drafting of formal agreements in the form of budgets or contracts, but also binding agreements approved with a simple yet formal handshake. For example, a CEO described an agreement reached with a professional manager as an economic exchange: "I agreed to increased annual marketing investments for the future. But 
in exchange, I obtained his involvement in training and mentoring two young family members in his department" (CEO). In contrast, in familial social interactions bargaining took place through value abstraction and expressions of affect. When individual goals differed, more general topics entered into the discussion while private communication was often used to convince others (e.g., invoking principles, past episodes in the family, and citing other family member experiences). Furthermore, individuals tended to calm tension with statements that emphasized their affect or their parental empathy: "I pretended to have more autonomy in a project, as it was important for me personally, and it was for my family too.... People were talking about my low reliability, but my father intervened in my favor by supporting my claims ... He said that every one of us must have an opportunity" (YG). In addition, stabilization took place in the form of mores (i.e., moral codes of conduct among individuals such as those between a father and his children or those referring to other family relationships) and folkways (i.e., socially accepted forms of behavior such as the observance of rituals or acknowledgment methods). During a dinner at the family home, for example, a young generation family manager had an argument with a professional manager. At one point, he was stopped by the father (the CEO) who simply told him: "That's enough, go back to your place". The young manager was immediately silenced. Similarly, in a firm where two brothers were serving as CEOs, folkways were commonly used to resolve conflicts: "After he [his brother] told me what his priorities are, I just accepted them.... As long as we are in charge, I have to trust him; otherwise it will be the end of our firm" (CEO). To summarize, the differences that emerged between professional and familial social interactions are reported in Table 3.

Insert Table 3 about here 
Collectively, this body of evidence reveals that goal diversity among organizational members is resolved in family firms with two distinct types of interaction processes, namely, professional and familial social interactions. Thus, our analysis provides further insights into the idiosyncrasies of goal setting processes in family firms:

Proposition 3: Professional social interactions involve administrative bargaining, whereas familial social interactions involve affective bargaining.

Proposition 4: In professional social interactions, stabilization is achieved through formal controls, whereas in familial social interactions stabilization follows social control mechanisms.

To sum up, the evidence presented thus far explains how family-centered goals enter the agenda of organizational members in family firms, pointing to two distinct social interaction processes through which family-centered goals are bargained and stabilized, and goal diversity is thus turned into a consistent course of actions to be applied by individual members. In the next section we further explore the consequences of these social interaction processes for organizational outcomes.

\section{Collective Commitment to Family-Centered Goals}

The differences between professional and familial social interaction processes have relevant implications on organizational outcomes. The actual implementation of family-centered goals requires organizational members to act on a common set of strategic priorities (Floyd \& Wooldridge, 1992), and the pursuit of family-centered goals lies at the base of distinctive family firm behaviors (Chrisman et al., 2012). Thus, understanding how family-centered goals are adopted by family firms, notwithstanding organizational member goal diversity, is the ultimate purpose of our study. 
Our data show that when bargaining was not followed by stabilization, the original goal divergences among organizational members continued to subsist. In contrast, after a stabilization mechanism was observed, the individuals typically communicated their satisfaction and expressed feelings of appreciation and loyalty to family values. For example, after a meeting between a CEO and his daughter who is also involved in the firm, she said, "I needed this confrontation to see the bigger picture and to share his [the CEO's] view" (YG). Likewise, a CEO was pleased about how a discussion with his brother - a shareholder not involved in the firm - was concluded: "When one speaks clearly and sincerely the relationship will benefit both parties. ...I will reconsider his [the brother's] position as part of the family" (CEO). In addition to organizational members conforming to family values, stabilization also engendered acts of resource dedication, where individuals stated their willingness to invest mental and physical energy towards family-centered goals: "Once I heard the motivations, I understood their importance ... I will give my full contribution" (PM); “A promise is a promise. ... Now I know where to direct my efforts" (PM).

In sum, the stabilization mechanisms in both professional and familial social interactions resulted in stronger commitment to family-centered goals by the members involved, as observed in terms of conformation to family values and resource dedication (see Figure 1). As reported in Table 4, instances of stabilization and the consequent acts of commitment to family-centered goals were observed in both professional and familial social interactions. The range of organizational membership categories of individuals involved is relatively similar for both acts of conformation to family values and resource dedication. More importantly, only 32 percent of professional interactions resulted in an act of commitment to family-centered goals, whereas in 
familial social interactions, acts of commitment to family-centered goals were observed in 74 percent of episodes.

\section{Insert Table 4 about here}

Professional and familial social interactions therefore emerge as two parallel yet distinct processes characterizing goal setting in family firms with different degrees of effectiveness in generating stabilization mechanisms around family-centered goals. In professional interactions, family-centered goals are bargained but are rarely stabilized, and goal diversity often remains unresolved. On the other hand, in familial social interactions the stabilization rate is much higher, suggesting greater effectiveness in bringing together diverse goals and triggering acts of commitment to family-centered goals. Thus, we propose:

Proposition 5: Stabilization of family-centered goals is more likely to occur through familial than professional social interactions.

The empirical observations presented above were particularly informative on how familycentered goals spread and become accepted among organizational members. We obtained data describing 165 goal-centered social interactions, at least 7 in each family firm. In each firm, both professional and familial social interactions were observed. Each time a stabilization mechanism took place, an organizational member expressed greater commitment to family-centered goals, as denoted by explicit statements indicating either conformation to family values or resource dedication. This evidence formed the premises from which to develop a collective construct (Morgeson \& Hofmann, 1999) to describe the extent to which the individual actions of the organizational members converge towards the accomplishment of family-centered goals. We call this construct collective commitment to family-centered goals:

Definition: The collective commitment to family-centered goals is a common mindset and a joint psychological state among family firm organizational 
members in terms of their feelings of loyalty to the family and the desire to invest mental and physical energy in helping to achieve family-centered goals.

Not only did the evidence presented thus far lead us to ground the concept of collective commitment in family-centered goals, but it also revealed several important details on how such commitment develops throughout the organization. Specifically, it showed that organizational members in family firms have the option to confront their goals through either professional or familial social interaction processes. In professional interactions, the family-centered goals are bargained but are rarely stabilized (see Table 4), and goal diversity is not resolved as individuals remain anchored to their own goals and refuse to put their efforts into accomplishing familycentered goals. As a consequence, we propose:

Proposition 6: The higher the reliance on professional social interactions, the lower the collective commitment to family-centered goals.

To the contrary, familial interactions were often followed by stabilization mechanisms in the form of social controls, which guided individuals to adjusting their own goals, to change their psychological state and to express commitment to family-centered goals (see Table 4). This led us to the interpretation that the formation of family-centered goals in family firms is favored by familial social interactions during which family members create norms of behavior that are consistent with the family vision, increasing organizational member commitment to familycentered goals. As a consequence, commitment to family-centered goals becomes more homogeneous with recurring familial social interactions among organizational members that are repeated over time. Thus, we argue:

Proposition 7: The higher the reliance on familial social interactions, the greater the collective commitment to family-centered goals. 
Based on the body of evidence and the propositions developed so far, in the next section we synthesize our findings to provide a comprehensive portrait of goal setting in family firms.

\section{Towards a Process View of Goal Setting in Family Firms}

To help interpret the various concepts and their relationships in our data, we constructed Figure 3, which summarizes and generalizes our main findings, graphically presenting the observations and propositions that emerged from our empirical analysis.

\section{Insert Figure 3 about here}

Mirroring the behavioral assumptions of organizational goal setting (Cyert \& March, 1963), our three initial observations describe the family firm as a collective, intended as an interdependent and goal-directed combination of individuals embedded in multiple organizational contexts. The overlap of the family system with ownership and management thus leads not only to the adoption of family-centered goals (Chrisman et al., 2012), but also entails goal diversity, working as a latent force in family firms that may generate resistance to the family coalition. Family firms may resolve goal diversity and promote the adoption of familycentered goals through social interaction processes. However, professional social interactions usually leave intact - and may even exacerbate - goal divergences, thus negatively affecting organizational member commitment to family-centered goals. To the contrary, family-centered goals can be stabilized more effectively through familial social interactions. These promote the resolution of goal divergences between organizational members in favor of the family's interests, and lead to the reinforcement of collective commitment to family-centered goals. Finally, the model in Figure 3 emphasizes the role of intra-family succession as a catalyst of change (P1). When an intra-family succession is imminent, the goals previously stabilized are unfrozen as the leadership and structure are likely to be reconsidered (De Massis et al., 2008; Le Breton-Miller, 
Miller, \& Steier, 2004). Thus, organizational members express their goals more fervently and activate social interactions that will lead to new stabilizations, and thus a new status quo, similar to Lewin's (1951) classic description of disruptive change as freezing-transition-unfreezing. In sum, our analysis clarifies how the adoption of family-centered goals in family firms stems from a continuous, composite and cyclical process of goal setting among multiple and diverse organizational members.

\section{DISCUSSION}

The adoption of family-centered goals is a distinctive trait of family firms and a central axiom in family business literature (e.g., Chrisman et al., 2005). Prior research theorized and empirically tested the link between family involvement and the adoption of family-centered goals (Chrisman et al., 2012; Chua et al., 1999). However, there is increasing consensus that goals vary among family firms (Chrisman et al., 2005; Westhead \& Howorth, 2007). This calls

for more careful attention in untangling the complexity of management processes resulting from systemic interactions between the family, the ownership and the business systems (Habbershon et al., 2003; Steier, Chua, \& Chrisman, 2009) to understand the processes underlying the adoption of family-centered goals and thus improve the predictive power of theories of the family firm.

In response, we conducted a qualitative study that provides new insight into how familycentered goals enter the operational agenda of family firms. Our findings disclose the multilevel dimensions of complexity that characterize family firms, adding factual evidence and new notions to our understanding of how multiple and divergent entities generate goal diversity in family firms and how such diversity is managed to create collective commitment to familycentered goals. Specifically, our propositions move the focus of prior research towards an 
original viewpoint that captures the complexity of goal setting in family firms with the concept of goal diversity. This perspective highlights the critical importance for family firms to manage goal diversity engendered by the unique systemic interactions between the family, the ownership and business systems. In this vein, the framework derived from our findings outlines two distinct social interaction processes through which goal diversity can be managed to build collective commitment to family-centered goals. While prior research primarily focused on family members pushing family-centered goals into the family firm agenda, our propositions suggest that for family-centered goals to be taken into consideration and affect the firm's strategic actions, these must be shared and embraced by a broader set of organizational members including, for example, professional managers as well as non-family shareholders. Finally, our propositions call attention to intra-family succession as a catalyst of change for organizational goals in family firms, thus offering an original portrait of goal setting that incorporates the multidimensional, dynamic and cyclical aspects of goal setting processes in family firms.

Our findings have theoretical and empirical implications. While family involvement in ownership and management remains a general predictor of the ability of a controlling family to influence the policies and decisions of a firm (Chrisman et al., 2012), the active participation of family members in the business is also shown to produce greater goal diversity among organizational members. This diversity may entail conflict among family and non-family managers, family and non-family shareholders, as well as among family members in different generations or with different degrees of involvement. Goal diversity is an accurate and fitting representation of the varied relations between the family, ownership, and business systems and points to the existence of new mediating mechanisms between family involvement and the adoption of family-centered goals. On the one hand, we show that familial social interactions act 
as a consistent (positive) mediator of the relationship between goal diversity and collective commitment to family-centered goals; on the other hand, professional social interactions act as an inconsistent (negative) mediator of the same relationship.

A more careful account of goal diversity in family firms and the internal processes of social interactions among organizational members would benefit the development of theories on the distinctive behaviors of family firms. Considering the causes and consequences of goal diversity within the family firm as a whole, or within specific decisional groups (e.g., the dominant coalition, the top management team) would enable a better prediction of the conditions under which family involvement in ownership and management lead to the adoption of familycentered goals in decision making (Chrisman et al., 2012). Furthermore, taking into consideration goal diversity and professional and familial social interactions would also benefit the accuracy of empirical research. Indeed, while the inclusion of a consistent mediator in a statistical model will reduce the main effect, the inclusion of an inconsistent mediator is acknowledged as increasing its predictive validity (MacKinnon, 2008).

Our study also adds to our knowdge of intra-family succession processes and indicates the decisive effects of intra-family succession for family-centered goals. Intra-family succession is one of the key topics in family business literature (De Massis et al., 2008) as this poses unique challenges for family firms. Our study adds to previous work in this sphere by showing that the imminence of a generational transition increases the expression of goal diversity in the organization and triggers unfreezing processes in relation to the previously stabilized goals and restabilization of new organizational goals, thus disentangling the dynamic and iterative nature of intra-family succession (Le Breton-Miller et al., 2004). 
In addition, our study has practical implications for families who wish to sustain the creation of wealth across generations of family control, finding in our model practical advice on the importance of establishing and managing goal setting processes during the intra-family succession phases. More broadly, managers and professionals working with family firms could make use of our findings to build practical solutions for business families wanting to spread family values and build collective commitment to family-centered goals in their firms without incurring relational conflicts with other organizational members. A more extensive use of familial social interactions could in fact be a viable pathway to building legitimacy for the controlling family and obtaining positive outcomes for both the business and the family. To the contrary, the exclusive discussion of family-centered goals through professional social interactions may be an ineffective - and possibly counterproductive - way to advance the values and vision of the family in the firm. Finally, our findings also encourage family firm advisors to more carefully implement conflict-resolution strategies in family firms since their effectiveness must be adjusted and contextualized to the different types of social interactions as emerging from our study.

\section{Limitations and Future Research Directions}

Our study is a first step to uncovering the intervening mechanisms that characterize goal setting in family firms, however, as any other qualitative study, it has a number of limitations that lay the foundations for future research. One area that deserves particular attention is the external validity of our findings, which must be tested and refined with statistical considerations. Our experience suggests that collecting data on goal setting processes in the family firm is difficult due to time and access constraints; therefore, creative approaches and innovative experimental designs are needed. Future research aspirations include capturing and linking the 
multiple notions proposed in this study with quantitative work in real and practical settings of how organizational goals are determined.

In relation to this, our purpose was to introduce new constructs to explain how organizational goals are formed in family firms, but refining and validating these constructs is outside of the scope of this article. Refining the original constructs proposed in this article and developing reliable scales to measure these constructs is thus proposed as a promising area for future research. For example, the construct of goal diversity requires further examination and more work is required to advance our understanding of its antecedents and consequences by exploring its meaning, its maximum shape and the potential existence of distinct types of goal diversity (e.g., see Harrison \& Klein, 2007).

Future research will further advance our understanding of internal dynamics in family firms if it factually models the relative influences among individual organizational members. Indeed, we recognize that organizational members of family firms may have different degrees of organizational discretion to influence the goal setting process. The theory of stakeholder salience (Mitchell et al., 1997), for example, could serve as a starting point to address this issue. Finally, we intentionally restricted our analysis to small and medium family firms. Although our focus allowed us to investigate goal formulation processes in an ideal situation where the influence of the controlling family is potentially more important than in other firms, we may have overlooked those family firms where greater organizational complexity could potentially lead to even greater goal diversity among organizational members. For similar reasons, while we only focused on the organizational members in family firms within the ownership, business and family domains, future research is encouraged to extend our line of thinking to other actors (e.g., strategic partners, institutions) that could presumably influence the goals pursued by these organizations. 
In addition to extending the external validity and generalizability of our findings, and relying on the notions introduced in this study to build new measurable constructs, future research could draw from the insights provided in this study to address interesting and unexplored questions that are relevant for the development of knowledge on family firms. In particular, our observation that family involvement entails superior goal diversity in the organization introduces a new perspective to the study of family firms and stimulates further research in the area of organizational behavior in family firms. For example, prior research emphasized the importance of conflicts engendered by goal incompatibilities (Carsrud, 2006) and divergences between individuals with diverse social identities and different goals (De Massis, 2012) on the perceived injustice of family and non-family members. This suggests that goal diversity in the family firm could have important implications for several organizational outcomes such as organizational citizenship, person-organization fit or cognitive uncertainty. To our knowledge, studies on organizational behavior in family firms are scarce, however, the existence of unique sources of complexity in the family firm organizational environment suggests that research in this area could benefit understanding of organizational behavior in family firms and refining organizational behavior theories. For instance, how do family and nonfamily members choose between professional and familial interactions? How are these two social interaction processes engaged in over time? Although outside the scope of our research, these could represent promising research questions for future studies to understand how behaviors such as voice, whistle-blowing, championing or issue selling occur in family firms.

\section{CONCLUSION}

Although family firms, as any other business organization, must focus their efforts on achieving positive economic performance, the unique and systemic conditions arising in family 
firms due to the interaction of the family unit, the business entity and individual family members, increase the complexity of strategy processes and performance outcomes. Accordingly, we have sought to illuminate the overlooked topic of goal setting in family firms. Understanding how multiple and competing goals enter the decision processes of family firms is critical for management scholars as well as practitioners. We ascertained the complexities and challenges of goal setting in family firms and developed a grounded framework that describes goal setting as a set of multiple concurrent processes, emphasizing the triggering role of intra-family succession. This adds to our knowledge of the link between family involvement and the adoption of familycentered goals, pointing to promising avenues for future research while offering practical insights on goal setting in family firms. We hope to have brought research and practice closer to understanding the unique constituencies of family firms and to effectively managing their idiosyncratic strategic processes.

\section{APPENDIX}

\section{Abbreviated Interview protocol}

1. Background information on the family firm.

2. What are your parental relations with the firm's controlling family?

3. Your ownership of firm shares.

4. Your role in the company.

5. Please indicate your personal goals in relation to the family firm (define what you are consciously trying to do in the family firm) or the goals the family firm should pursue in your opinion. Please discuss why these goals are important to you and when and how the firm could accomplish such goals.

6. Are your claims important to other organization members? Why? Please give examples.

7. Please discuss and give examples of when, why and how you discuss your goals with other organizational members.

8. Please describe your influence on the goal formulation processes. Please give examples. 


\section{REFERENCES}

Argote, L., \& Greve, H.R. (2007). A behavioral theory of the firm-40 years and counting: Introduction and impact. Organization Science, 18(3), 337-349.

Astrachan, J.H., \& Jaskiewicz, P. (2008). Emotional returns and emotional costs in privately held family businesses: Advancing traditional business valuation. Family Business Review, 21(2), 139-149.

Cameron, K. (1978). Measuring organizational effectiveness in institutions of higher education. Administrative Science Quarterly, 23(4), 604-632.

Carsrud, A.L. (2006). Commentary: "Are we family and are we treated as family? Nonfamily employees' perceptions of justice in the family firm": It all depends on perceptions of family, fairness, equity, and justice. Entrepreneurship Theory and Practice, 30(6), 855860.

Chrisman, J.J., \& Patel, P.J. (2012). Variations in R\&D investments of family and non-family firms: Behavioral agency and myopic loss aversion perspectives. Academy of Management Journal, 55(4), 976-997.

Chrisman, J.J., Chua, J.H., \& Sharma, P. (2005). Trends and directions in the development of a strategic management theory of the family firm. Entrepreneurship Theory and Practice, 29(5), 555-576.

Chrisman, J.J., Chua, J.H., Pearson, A.W., \& Barnett, T. (2012). Family involvement, family influence, and family-centered non-economic goals in small firms. Entrepreneurship Theory and Practice, 36(2), 267-293.

Chua, J.H., Chrisman, J.J., \& Sharma, P. (1999). Defining the family business by behavior. Entrepreneurship Theory and Practice, 23(4), 19-39.

Corbetta, G., \& Salvato, C. (2004). Self serving or self actualizing? Models of man and agency costs in different types of family firms: A commentary on "Comparing the agency costs of family and non family firms: Conceptual issues and exploratory evidence". Entrepreneurship Theory and Practice, 28(4), 355-362.

Cyert, R.M., \& March, J.G. (1963). A behavioral theory of the firm. Englewood Cliffs, NJ: Prentice-Hall.

De Massis, A. (2012). Family involvement and procedural justice climate among non-family managers: The effects of affect, social identities, trust and risk of non-reciprocity. Entrepreneurship Theory and Practice, 36(6), 1227-1234.

De Massis, A., Chua, J.H., \& Chrisman, J.J. (2008). Factors preventing intra family succession. Family Business Review, 21(2), 183-199. 
De Massis, A., Kotlar, J., Chua, J.H., \& Chrisman, J.J. (forthcoming). Ability and willingness as sufficiency conditions for family-oriented particularistic behavior: Implications for theory and empirical studies. Journal of Small Business Management.

De Massis, A., Sharma, P., Chua, J.H., Chrisman, J.J., \& Kotlar, J. (2012). State-of-the-art of family business research. In A. De Massis, P. Sharma, J.H. Chua \& J.J. Chrisman (Eds.), Family business studies: An annotated bibliography (pp. 10-46). Northhampton, MA: Edward Elgar.

De Vries, M. (1993). The dynamics of family controlled firms: The good and the bad news. Organizational Dynamics, 21(3), 59-71.

Eisenhardt, K.M. (1989). Building theories from case study research. Academy of Management Review, 14(4), 532-550.

Floyd, S.W., \& Wooldridge, B. (1992). Managing strategic consensus: The foundation of effective implementation. Academy of Management Executive, 6(4), 27-39.

Folkman, S., \& Moskowitz, J.T. (2000). Positive affect and the other side of coping. American Psychologist, 55(6), 647-654.

Gómez-Mejía, L.R., Nunez-Nickel, M., \& Gutierrez, I. (2001). The role of family ties in agency contracts. Academy of Management Journal, 44(1), 81-95.

Guest, G., Bunce, A., \& Johnson, L. (2006). How many interviews are enough? Field Methods, 18(1), 59-82.

Habbershon, T.G., Williams, M., \& MacMillan, I.C. (2003). A unified systems perspective of family firm performance. Journal of Business Venturing, 18(4), 451-465.

Harrison, D.A., \& Klein, K.J. (2007). What's the difference? Diversity constructs as separation, variety, or disparity in organizations. Academy of Management Review, 32(4), 11991228.

Hitt, M.A., Beamish, P.W., Jackson, S.E., \& Mathieu, J.E. (2007). Building theoretical and empirical bridges across levels: multilevel research in management. Academy of Management Journal, 50(6), 1385-1399.

Jacobides, M.G. (2007). The inherent limits of organizational structure and the unfulfilled role of hierarchy: Lessons from a near-war. Organization Science, 18(3), 455-477.

Jensen, M.C., \& Meckling, W.H. (1976). Theory of the firm: Managerial behavior, agency costs and ownership structure. Journal of Financial Economics, 3(4), 305-360.

Komorita, S.S., \& Chertkoff, J.M. (1973). A bargaining theory of coalition formation. Psychological Review, 80(3), 149-162.

La Porta, R., Lopez-de-Silanes, F., Shleifer, A., \& Vishny, R. (1999). Corporate ownership around the world. Journal of Finance, 54(2), 471-517. 
Le Breton-Miller, I.L., Miller, D., \& Steier, L.P. (2004). Toward an integrative model of effective FOB succession. Entrepreneurship Theory and Practice, 28(4), 305-328.

Lewin, K. (1951). Field theory in social science. New York: Harper.

Locke, K. (2001). Grounded theory in management research. London, U.K.: Sage.

MacKinnon, D.P. (2008). Introduction to statistical mediation analysis. Mahwah, NJ: Lawrence Erlbaum Associates.

Miles, M.B., \& Huberman, A.M. (1999). Qualitative data analysis. Beverly Hills, CA: Sage.

Mitchell, R.K., Agle, B.R., \& Wood, D.J. (1997). Toward a theory of stakeholder identification and salience: Defining the principle of who and what really counts. Academy of Management Review, 22(4), 853-886.

Morgeson, F.P., \& Hofmann, D.A. (1999). The structure and function of collective constructs: Implications for multilevel research and theory development. Academy of Management Review, 24(2), 249-265.

Paulhus, D.L. (1984). Two-component models of socially desirable responding. Journal of Personality and Social Psychology, 46(3), 598-609.

Pearce, J.A., \& DeNisi, A.S. (1983). Attribution theory and strategic decision making: An application to coalition formation. Academy of management Journal, 26(1), 119-128.

Pfeffer, J., \& Salancik, G.R. (1977). Organization design: The case for a coalitional model of organizations. Organizational Dynamics, 6(2), 15-29.

Pitcher, P., \& Smith, A.D. (2001). Top management team heterogeneity: Personality, power, and proxies. Organization Science, 12(1), 1-18.

Rosenthal, H. (1970). Size of coalition and electoral outcomes in the fourth french republic. In S. Groennings, E. W. Kelley \& M. Leiserson (Eds.), The study of coalition behavior (pp. 43-59). New York: Holt, Rinehart \& Winston.

Schulze, W.S., Lubatkin, M.H., \& Dino, R.N. (2003). Exploring the agency consequences of ownership dispersion among the directors of private family firms. Academy of Management Journal, 46(2), 179-194.

Simon, H.A. (1964). On the concept of organizational goal. Administrative Science Quarterly, 9(1), 1-22.

Steier, L.P., \& Miller, D. (2010). Pre-and post-succession governance philosophies in entrepreneurial family firms. Journal of Family Business Strategy, 1(3), 145-154.

Steier, L.P., Chua, J.H., \& Chrisman, J.J. (2009). Embeddedness perspectives of economic action within family firms. Entrepreneurship Theory and Practice, 33(6), 1157-1167. 
Stevenson, W.B., Pearce, J.L., \& Porter, L.W. (1985). The concept of "Coalition" in organization theory and research. Academy of Management Review, 10(2), 256-268.

Tagiuri, R., \& Davis, J.A. (1992). On the goals of successful family companies. Family Business Review, 5(1), 43-62.

Villanueva, J., \& Sapienza, H.J. (2009). Goal tolerance, outside investors, and family firm governance. Entrepreneurship Theory and Practice, 33(6), 1193-1199.

Wengraf, T. (2001). Qualitative research interviewing: Biographic narrative and semistructured methods. Thousand Oaks, CA: Sage.

Westhead, P., Cowling, M., \& Howorth, C. (2001). The development of family companies: Management and ownership imperatives. Family Business Review, 14(4), 369-385.

Westhead, P., \& Howorth, C. (2007). 'Types' of private family firms: An exploratory conceptual and empirical analysis. Entrepreneurship \& Regional Development, 19(5), 405-431. 


\section{Table 1}

\section{General Information on Data Sources and Informants ${ }^{\mathrm{a}}$}

\begin{tabular}{|c|c|c|c|c|c|}
\hline \multicolumn{4}{|c|}{ Informant Distribution Across Firms } & \multicolumn{2}{|c|}{ Informant Characteristics } \\
\hline Firm & $\begin{array}{c}\text { Informants by } \\
\text { Organizational Role }\end{array}$ & $\begin{array}{c}\text { No. of } \\
\text { Meetings } \\
\text { Observed }\end{array}$ & $\begin{array}{c}\text { No. of } \\
\text { Archival } \\
\text { Files } \\
\text { Collected }\end{array}$ & $\begin{array}{c}\text { Individual Level } \\
\text { Information }\end{array}$ & $\begin{array}{c}\text { No. of } \\
\text { Informants } \\
(\%)\end{array}$ \\
\hline 1 & CEO, PM, YG, OG & 6 & 3 & Organizational role ${ }^{b}$ & \\
\hline 2 & CEO, PM, YG & 3 & 2 & CEO & $21(27 \%)$ \\
\hline 3 & CEO, PM, 2 YG & 5 & 7 & $\mathrm{CS}$ & $5(7 \%)$ \\
\hline 4 & CEO, PM, OG & 4 & 4 & $\mathrm{PM}$ & $20(26 \%)$ \\
\hline 5 & CEO, CS, PM, 2 YG & 9 & 1 & YG & $25(33 \%)$ \\
\hline 6 & CEO, PM, YG & 4 & 4 & OG & $5(7 \%)$ \\
\hline 7 & $\mathrm{CEO}, \mathrm{CS}, \mathrm{PM}$ & 5 & 9 & & \\
\hline 8 & CEO, PM, 2 YG, OG & 8 & 6 & Involvement in the businesss ${ }^{b}$ & \\
\hline 9 & CEO, PM, YG & 5 & 1 & Actively involved & $64(84 \%)$ \\
\hline 10 & CEO, PM, YG & 6 & 5 & Not actively involved & $12(16 \%)$ \\
\hline 11 & CEO, PM, YG & 4 & 2 & & \\
\hline 12 & CEO, CS, PM, YG & 6 & 7 & Family membership ${ }^{b}$ & \\
\hline 13 & $2 \mathrm{CEO}, \mathrm{CS}, 3 \mathrm{PM}, 2 \mathrm{YG}, \mathrm{OG}$ & 12 & 5 & Family member & $56(74 \%)$ \\
\hline 14 & CEO, PM, 2 YG & 6 & 3 & Non-family member & $20(26 \%)$ \\
\hline 15 & CEO, PM, YG & 4 & 6 & & \\
\hline 16 & $2 \mathrm{CEO}, \mathrm{CS}, 3 \mathrm{YG}, \mathrm{OG}$ & 8 & 4 & Family member generation $^{c}$ & \\
\hline 17 & CEO, PM, YG & 5 & 1 & Young generation & $25(45 \%)$ \\
\hline 18 & CEO, PM, YG & 5 & 7 & Current generation & $26(46 \%)$ \\
\hline 19 & CEO, PM, 2 YG & 9 & 6 & Older generation & $5(9 \%)$ \\
\hline
\end{tabular}

Notes. CEO, Chief Executive Officer. CS, CEO’s spouse. PM, professional manager. YG, young generation family member. OG, old generation family member.

${ }^{a}$ The names of the sampled family firms, organizational members and other identifying information presented here have been omitted to protect the anonymity of our informants.

${ }^{\mathrm{b}}$ Total population of organizational members, $\mathrm{N}=76$.

${ }^{\mathrm{c}}$ Family members, $\mathrm{N}=56$. 
Table 2

Organizational Member Goals in the Family Firm by Goal Content and Goal Recipient

\begin{tabular}{ccc}
\hline \multirow{2}{*}{ Goal Content } & Gamily & Noal Recipient \\
\cline { 2 - 3 } & Family control over the company & Firm growth \\
\hline Fonily wealth & Firm survival \\
& Family harmony & Firm economic performance \\
& Family social status & Firm internal serenity \\
& Family identity linkage & External relations \\
\hline
\end{tabular}

Table 3

Differences between Professional and Familial Social Interaction Processes

\begin{tabular}{lcc}
\hline & Professional Social Interactions & Familial Social Interactions \\
\hline Setting & Business environment only & Business and family environment \\
Norms & Schedules and defined roles & Irregularity and ambiguous roles \\
Means of Bargaining & Promises of rewards, threats of sanctions & Value abstraction, expressions of affect \\
Means of Stabilization & Formal agreement & Social control \\
\hline
\end{tabular}

Table 4

Stabilizations and Acts of Commitment to Family-Centered Goals by Organizational Membership of Informants

\begin{tabular}{|c|c|c|c|c|c|c|c|}
\hline & \multicolumn{3}{|c|}{$\begin{array}{c}\text { Acts of Conformation } \\
\text { to Family Values }\end{array}$} & \multicolumn{3}{|c|}{ Resource Dedication } & \multirow[b]{2}{*}{ Total } \\
\hline & $\begin{array}{c}\text { Family } \\
\text { Members }\end{array}$ & Shareholders & $\begin{array}{l}\text { Actively } \\
\text { Involved }\end{array}$ & $\begin{array}{c}\text { Family } \\
\text { Members }\end{array}$ & Shareholders & $\begin{array}{l}\text { Actively } \\
\text { Involved }\end{array}$ & \\
\hline $\begin{array}{l}\text { Professional } \\
\quad \text { Social } \\
\text { Interactions }^{\mathrm{a}}\end{array}$ & $18 \%$ & $27 \%$ & $21 \%$ & $26 \%$ & $22 \%$ & $29 \%$ & $32 \%$ \\
\hline $\begin{array}{c}\text { Familial } \\
\text { Social } \\
\text { Interactions }^{\text {b }} \\
\end{array}$ & $66 \%$ & $50 \%$ & $48 \%$ & $78 \%$ & $53 \%$ & $58 \%$ & $74 \%$ \\
\hline
\end{tabular}




\section{Figure 1}

\section{Overview of Data Structure}

\section{First-Order Codes}

\section{Second-Order Themes}

\section{Aggregate Theoretical Dimensions}

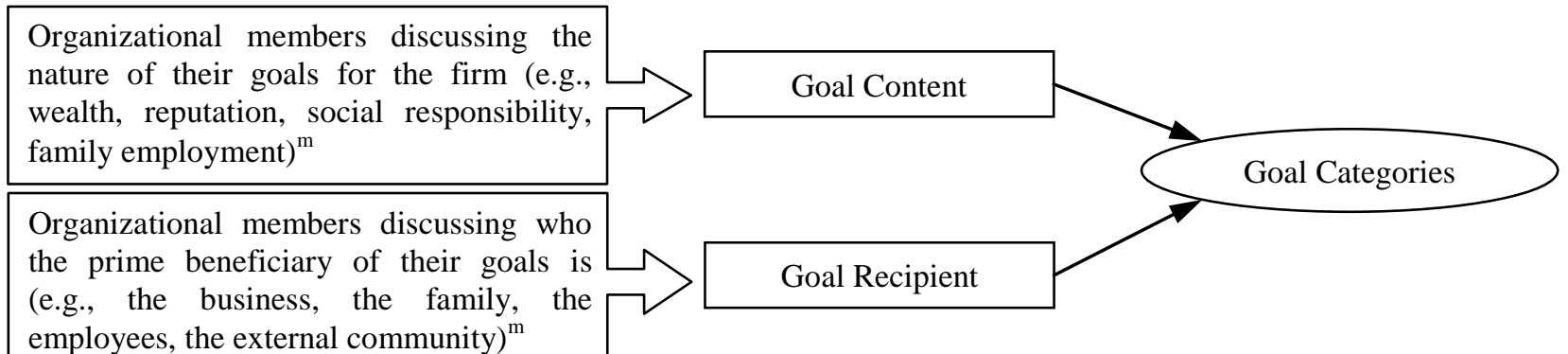

${\text { employees, the external community })^{\mathrm{m}}}^{\mathrm{m}}$

Organizational members referring to a goal as meaning "successful", "right" or "pleasant"m

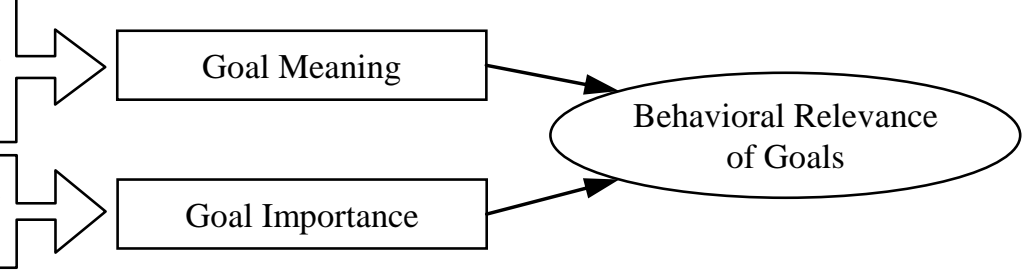

Statements such as "it is important" or "I care" referred to a goal $^{\mathrm{m}}$

Episodes of intra-member settlements and
disputes (e.g., organizational members
discussing their goals with other
members)

Organizational members expressing feelings of loyalty to the family or willingness to embrace the values and vision of the family ${ }^{\mathrm{m}}$

Organizational members putting forward material or mental resources to help solve issues related solely to the family ${ }^{\mathrm{m}}$

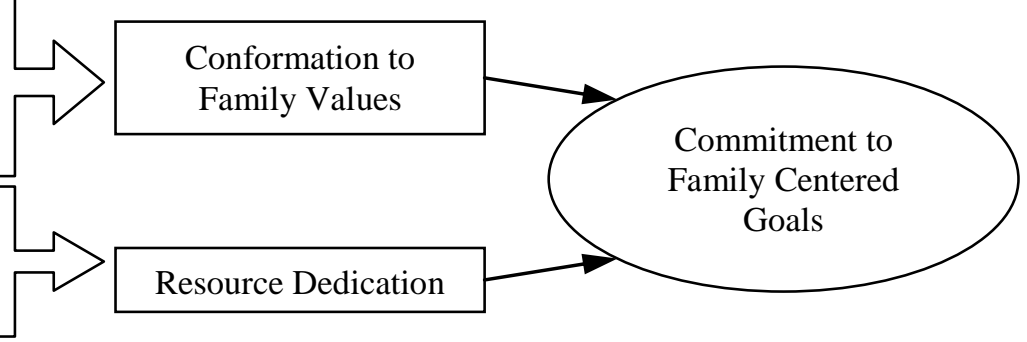

"All data were derived from semi-structured interviews; "m" indicates "supplemented with meeting observations"; and "d" indicates "supplemented with archival data". 
Figure 2

Goal Diversity in the Studied Firms by Stage of Intra-Family Succession ${ }^{\text {a }}$

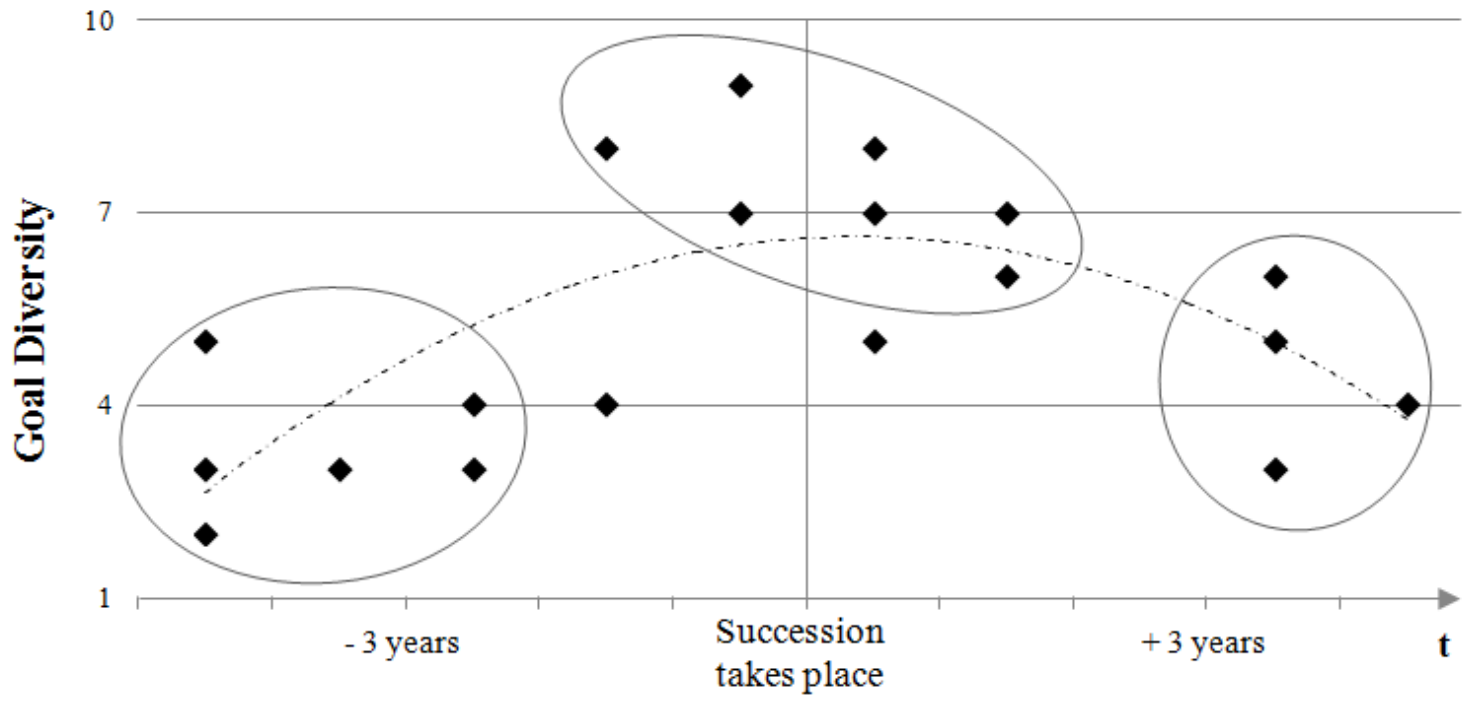

${ }^{a}$ Goal diversity is proxied by the number of different goals that emerged from interviews at the firm level.

Figure 3

A Process View of Goal Setting in Family Firms

Determinants of Organizational Goal Diversity Goal Setting Processes

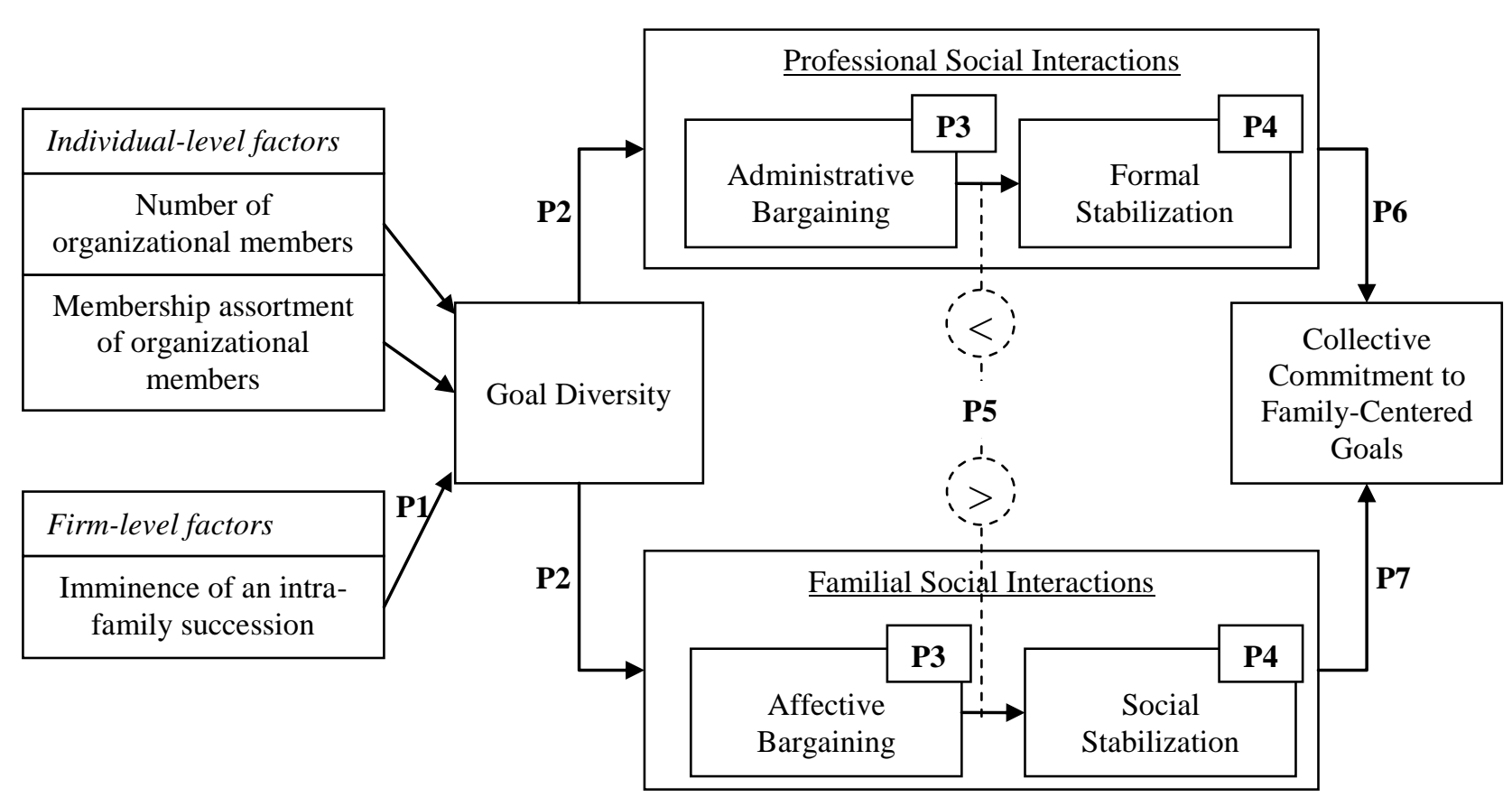

